\title{
Lycopene prevents cisplatin-induced liver tissue damage, without affecting concentrations of TNF- $\alpha$ or iNOS/NO inflammatory pathway
}

\section{Type}

Research paper

\section{Keywords}

macrophages, inflammation, lycopene, cisplatin, liver

\begin{abstract}
Introduction

Liver inflammatory response occurring after toxic chemicals injection, such as cisplatin, causes the aggravation in liver damage. Lycopene, a carotenoid, has previously been proven to possess antioxidant, antiinflammatory and antiapoptotic properties. This study objective was to evaluate for the first time the protective effects of lycopene in cisplatin-induced liver damage based on the disturbances in serum and tissue inflammatory parameters. Also, to confirm the extent of changes in inflammation of the studied tissue, a microscopic analysis will be performed.

\section{Material and methods}

Wistar rats were divided into four experimental groups: (I) control; (II) lycopene (2 mg/kg); (III) cisplatin $(10 \mathrm{mg} / \mathrm{kg}$ ) and (IV) lycopene and cisplatin-treated (2 and $10 \mathrm{mg} / \mathrm{kg}$, respectively) animals. After the experiment, we studied changes in serum liver tissue damage associated parameters (ALT, AST, and $\gamma-\mathrm{GT}$ ) and liver inflammatory parameters (NO and TNF- $\alpha$ concentrations, myeloperoxidase and iNOS activity, as well as CD68 expression).
\end{abstract}

\section{Results}

Application of lycopene prevented a rise in evaluated serum parameters induced by cisplatin, while at the same time it did not cause any harmful effect by itself. Lycopene, alone or in combination with cisplatin, decreased the values of all studied liver inflammatory parameters.

\section{Conclusions}

We can conclude that lycopene does not prevent liver tissue inflammatory decalin seen after cisplatin application, however, it prevents tissue damage arising from this cytostatic application. 
Lycopene prevents cisplatin-induced liver tissue damage, without affecting concentrations of TNF- $\alpha$ or iNOS/NO inflammatory pathway

Aleksandar Ranković ${ }^{\text {, Vanja P. Ničković }}$, Tatjana R. Novakovićc ${ }^{3}$, Nebojša R. Mitić3 ${ }^{3}$ Biljana Krdžić ${ }^{3}$, Jadranka S. Mitić ${ }^{3}$, Gordana Nikolić ${ }^{3}$, Dusan Sokolovićc,*

${ }^{1}$ Clinic for Infectious Diseases, Clinical Centre Niš and University of Niš, Faculty of Medicine, Niš, Serbia

${ }^{2}$ Clincal Centre Priština, Gračanica, Serbia

${ }^{3}$ Faculty of Medicine, University of Priština, Kosovska Mitrovica, Serbia

${ }^{4}$ Department of Biochemistry, Faculty of Medicine, University of Niš, Serbia

*Corresponding author: Dušan T Sokolović, Department of Biochemistry, Faculty of Medicine, University of Niš, Zorana Đinđića 81, 18000 Niš, Serbia; Phone number: +381642136478; Fax: +381.18238770; e-mail: dusantsokolovic@gmail.com

Running head: Lycopene does not affect liver inflammation 


\begin{abstract}
Introduction: Liver inflammatory response occurring after toxic chemicals injection, such as cisplatin, causes the aggravation in liver damage. Lycopene, a carotenoid, has previously been proven to possess antioxidant, antiinflammatory and antiapoptotic properties. This study objective was to evaluate for the first time the protective effects of lycopene in cisplatin-induced liver damage based on the disturbances in serum and tissue inflammatory parameters. Also, to confirm the extent of changes in inflammation of the studied tissue, a microscopic analysis will be performed.
\end{abstract}

Methods: Wistar rats were divided into four experimental groups: (I) control; (II) lycopene (2 $\mathrm{mg} / \mathrm{kg}$ ); (III) cisplatin (10 mg/kg) and (IV) lycopene and cisplatin-treated (2 and $10 \mathrm{mg} / \mathrm{kg}$, respectively) animals. After the experiment, we studied changes in serum liver tissue damage associated parameters (ALT, AST, and $\gamma$-GT) and liver inflammatory parameters (NO and TNF- $\alpha$ concentrations, myeloperoxidase and iNOS activity, as well as CD68 expression).

Results: Application of lycopene prevented a rise in evaluated serum parameters induced by cisplatin, while at the same time it did not cause any harmful effect by itself. Lycopene, alone or in combination with cisplatin, decreased the values of all studied liver inflammatory parameters.

Conclusions: We can conclude that lycopene does not prevent liver tissue inflammatory decalin seen after cisplatin application, however, it prevents tissue damage arising from this cytostatic application.

Key words: lycopene, liver, cisplatin, inflammation, macrophages 


\section{Introduction}

Cisplatin (CIS) is a platinum-containing chemotherapeutic agent, belonging to a group of alkylating agents, which can be used alone or in combination with other cytostatic drugs. Although side effects related to $\mathrm{CP}$ application primarily do not include hepatotoxicity, it is known that this chemotherapeutic agent administered as either high single doses or in repeated low doses significantly damages liver tissue [1]. Chemical interactions between CP and intracellular components lead to the formation of the highly electrophilic molecules which consequentially react with sulfhydryl groups, destabilize biological membranes, disrupt energy metabolism, and generate reactive oxygen species (ROS) [2].

Apart from these mechanisms of liver tissue damage, CP is known to cause the transcription of numerous pro-inflammatory genes, e.g. cyclooxygenase $(\mathrm{COX})$ and inducible nitric oxide synthase (iNOS), and activates Toll-like receptor-4 (TLR-4) [3]. However, there are studies suggesting that $\mathrm{CP}$ causes, both in in vitro and in vivo conditions, the suppression of tissue inflammation [4,5]. In the liver, major inflammatory cells that are known to modulate tissue response to toxic chemicals are tissue macrophages i.e. Kupffer cells [6]. These cells have both physiological and pathophysiological role in liver tissue functioning, and their inhibition if often related to the diminution in liver damage [7].

Lycopene (Lyp) represents one of the most powerful natural antioxidants that can be found in tomatoes, watermelons, apricots, papayas, etc. [8]. It's antioxidant and antiradical scavenging activities are tightly related to conjugated double bonds present in Lyp molecule [8]. Since a great number of organ dysfunctions arrive due to impairment in cell/tissue oxidant state application of Lyp found its application in the traditional medicine of many nations. Also, buy contributing to the prevention of apoptosis or some other signaling pathways Lyp can modify inflammatory response as well [8]. The effect of Lyp in serval models of liver damage induced by different hepatotoxic agents has been previously published $[9,10]$. However, up to now, there are no studies that evaluate the effects of Lyp on CP-induced rat liver damage or to the changes in tissue inflammatory response.

Having these facts in mind we aimed to evaluate the potential of Lyp in preventing rat liver tissue inflammatory disturbances occurring after $\mathrm{CP}$ administration. The hepatoprotective potential of Lyp would be estimated based on the changes in serum liver tissue damage associated parameters 
and based on the disturbance in tissue inflammatory parameters. Also, in order to confirm the extent of changes in inflammation of the studied tissue and the effects of Lyp microscopic analysis will be performed.

\section{Experimental}

\section{Drugs and chemicals}

All reagents, solvents, and drugs used in this investigation were of analytical grade or better and were obtained from Sigma-Aldrich (St. Louis, MO, USA) or Richter Pharma AG (Wels, Austria). Lycopene solution was prepared daily, in corn oil, prior to the administration at a dose of $2 \mathrm{mg} / \mathrm{kg}$.

\section{Animals and housing}

Twenty-four male Wistar rats (250-300 g) were kept under standard laboratory conditions in plexiglass cages: $22 \pm 2{ }^{\circ} \mathrm{C}$ temperature, $60 \%$ humidity, and 12/12 (light/dark) cycle. Food and water were available ad libitum throughout the experiment. All experimental procedures were conducted in compliance with the European Council Directive (EU Directive of 2010; 2010/63/EU) and were approved by the local Ethics committee.

\section{Experiment design}

Liver tissue damage induced by $\mathrm{CP}$ was performed according to a previous publication [11]. Groups of animals were treated for five days as follows:

I Group - Vehicle treated group - received a daily injection of vehicle $1 \mathrm{~mL} / \mathrm{kg}$;

II Group - Lyp treated group - received a daily injection of Lyp (2 mg/kg) for five days;

III Group - CP treated group - received CP injection $(10 \mathrm{mg} / \mathrm{kg})$ on the $3^{\text {rd }}$ day of the experiment;

IV Group - CP and Lyp treated group - received Lyp for five days ( $2 \mathrm{mg} / \mathrm{kg}$ ), and a single injection of CP $(10 \mathrm{mg} / \mathrm{kg})$ on the $3^{\text {rd }}$ day.

Twenty-four hours after the last treatment all animals were sacrificed with an overdose of ketamine, a blood sample was taken by cardiac puncture, and liver tissue was removed for tissue biochemical (frozen and stored at $-80^{\circ} \mathrm{C}$ ) and histopathological (fixated in $10 \%$ buffered formalin) analyses. 


\section{Biochemical analysis}

\section{Serum biochemical analysis}

Collected blood samples were left to clot at room temperature before the serum was separated by centrifugation at $2500 \mathrm{rpm}$ for $10 \mathrm{~min}$. Separated serums were used for the determination of biochemical parameters that reflect the functional state of the liver. Aspartate transaminase (AST), alanine transaminase (ALT) and gamma-glutamyl transferase $(\gamma-\mathrm{GT})$ levels were assayed by an Olympus AU680 Chemistry-Immuno Analyzer (Olympus America Inc., USA).

\section{Tissue homogenization, protein content and inflammatory parameters determination}

After defrosting tissue samples were chopped into small pieces and homogenized in ice-cold distilled water and centrifuged afterward $\left(5000 \mathrm{rpm}, 15 \mathrm{~min}, 4^{\circ} \mathrm{C}\right)$. The obtained supernatant was further used for biochemical parameter estimation. Tissue protein content was determined in supernatants following Lowry's method [12].

Tissue NO concentrations were estimated based on the formed $\mathrm{NO}^{2-}$, using the standard Griess reaction and the nitrite concentrations were calculated using a standard curve of sodium nitrite [13]. The activity of myeloperoxidase (MPO) was determined in tissue homogenates following the previously described method [14] which is based on the reaction between 1,2-diaminobenzene and $\mathrm{H}_{2} \mathrm{O}_{2}$ under acidic conditions.

Levels of tumor necrosis factor $\alpha$ (TNF- $\alpha$ ), inducible nitric oxide synthase (iNOS) and CD68 in liver tissue homogenates were determined using Abcam (ab100785; Cambridge, United Kingdom) and CUSABIO (CSB-E08325r and CSB-E13297r; Huston, Texas, USA) ELISA kits. The range of the calibration curves for the TNF- $\alpha$, iNOS and CD68 were the following 18.75-1200 pg/ml, $0.78-50 \mathrm{IU} / \mathrm{mL}$ and $0.625-40 \mathrm{ng} / \mathrm{mL}$, respectively.

\section{Histopathological analysis}

Isolated liver tissue was fixed in formaldehyde solution $(10 \%, \mathrm{w} / \mathrm{v})$, further dehydrated with ethanol of differing ascending concentrations (50-100\%, v/v), embedded in paraffin molds and cut into 4-5 $\mu \mathrm{m}$-thick sections. Tissue sections were routinely stained with hematoxylin and eosin (HE), and further examined with Leica (Mycroastrms, Germany) light microscope equipped with 
a Canon PowerShot S70 camera. An average number of Kupffer cells per high power field (HPF) (magnification $\mathrm{x} 400$ ) was counted on at least 10 different fields per liver sample.

\section{Statistical analysis}

Data presented are mean values $\pm \mathrm{SD}$ and were compared using one-way analysis of variance (ANOVA), followed by Tukey's post hoc test for multiple comparisons (GraphPad Prism, ver. 5.03; San Diego, CA, USA). Probability values (p) less than 0.05 were considered to be statistically significant.

\section{Results}

Application of CP lead to a statistically significant increase, compared to the control group, in the activity of the studied serum liver damage related enzymes (Table 1). In the group IV, the one receiving Lyp and CP, the serum activity of all studied enzymes was in the same range as the activity determined in untreated animals (group I), however significantly decreased compared to group III was only found for AST and $\gamma$-GT activities (Table 1).

\section{Table 1 should be around here}

Studied inflammatory parameters included NO, CD68 and TNF- $\alpha$ concentrations, as well as MPO and iNOS activities which were all detectable to some extent in liver tissue homogenate (Table 2). Application of $\mathbf{L y p}$, both alone or in combination with CP, lead to a significant decrease $(\mathrm{p}<0.001)$ in the concertation/activity of all studied parameters compared to the control group (Table 2). Similar, almost identical, results to that of the Lyp treated groups for the studied biochemical parameters were obtained from livers of animals that received CP only ( $>0.05$ vs. Lyp treated group).

\section{Table 2 should be around here}

The counted average number of macrophages per HPF was not found to be significantly different between the experimental groups (Fig. 1 and 2), i.e. the number of macrophages was almost identical in all four experimental groups.

Figure 1 and 2 should be around here 


\section{Discussion}

Liver cell integrity and function that is known to be compromised after CP application [1] and the influence of Lyp was studied through the changes in liver tissue derived enzyme activities in experimental animals' serum. Here again, similar to the results of the previous publications $[9,10]$, we found that Lyp protects liver tissue from the damaging agent, in this case from $\mathrm{CP}$, judged by the changes in serum ALT, AST and $\gamma$-GT activities (Table 1). The mechanism that might underline this hepatoprotective activity of Lyp is probably related to its ability to scavenge free radicals generated by CP [8]. However, there is little information regarding the effects of Lyp on liver tissue inflammatory response arising after different toxicant application.

Various inflammatory stimuli are known to cause significant alterations in liver macrophage functioning by upregulating a large panel of pro-inflammatory molecules, growth factors, and reactive oxygen species [6]. Some of those molecules, such as NO, MPO, iNOS, TNF- $\alpha$ and CD68, which are produced by Kupffer cells were evaluated in our study in order to determine what kind of impact does Lyp and CP, alone or in combination, have on them. All of the evaluated biomarkers represent constitutive molecules/enzymes present in Kupffer cells, however, their activity/concertation is significantly increased in the presence of some pro-inflammatory stimulus [6].

Although CD68 doesn't have a central role in regulating innate and adaptive immune responses this lysosome/membrane-bound highly glycosylated signal peptide is still a valuable marker that enables us to track the function/activity of Kupffer cells [15]. The role of CD68 is still debatable, however, it is known that this molecule is involved in antigen processing and presentation and in some aspects in the process of apoptosis and Kupffer cell activation [5,15]. Up to know there are no studies showing the effects of CP on liver CD68 concertation, and here for the first time, we found that a single $10 \mathrm{mg} / \mathrm{kg}$ injection of CP causes a significant decrease in CD68 rat liver concertation (Table 2). On few previous occasions, results of different studies showed contradictory findings, where in one case CP application increases kidney CD68 expression [16], while in the other CP application decreased lymphoid tissue (thymus, spleen) CD68 expression [5]. Also, one of the interesting findings of this study is that Lyp on its own decreases CD68 expression, which corroborates the previous publication which suggests that this carotenoid possesses strong anti-inflammatory activity [9]. 
Various proinflammatory signals such as ROS lead to an increase in macrophage MPO activity as well as to an increase in NO production through iNOS [17]. Excesses in both MPO activity and NO concentrations are tightly related to liver tissue damage [18,19]. Here again, the results of previous studies related to CP influence on inflammatory parameters are controversial [16,20,21], however, some of them agree with the ones obtained in our study (Table 2). Regarding the effects of Lyp on NO/iNOS system and MPO activity the results of our study only partially agree with previous publications [22,23]. Application of Lyp decreased MPO and iNOS activity, as well as NO concentrations, while when it was applied together with $\mathrm{CP}$ it had no significant influence (compared to the CP treated group). This again underlines the studies which suggest that Lyp suppresses inflammatory cell function, however, this might not be a complete suppression since still a certain degree of $\mathrm{NO}$, higher than in the $\mathrm{CP}$ group, was present.

The evaluated chemokine TNF- $\alpha$ is an important signaling molecule [24-26], released from Kupffer cells, which is related to liver fibrosis and activation of the hemostatic system [6]. The results of our study for the first time revealed that Lyp decreases TNF- $\alpha$ production in healthy animals, which is completely opposite from previous studies where Lyp increased liver TNF- $\alpha$ production [27]. These discrepancies could be interpreted through different doses applied to animals, as well as to the length of the experiments [27]. Regarding the effect of CP, some publications suggest that CP reduce the inflammatory response of the studied macrophages by decreasing TNF- $\alpha$ and interferon- $\gamma$ concentrations in cell supernatants [20]. On the other hand, much higher concentrations of CP $(10 \mu \mathrm{g} / \mathrm{ml})$ induce the inflammatory response, characterized by an increase in NO and proinflammatory cytokines, in macrophage culture [20].

As stated, the application of Lyp on its own produced the inhibition of all studied inflammationrelated parameters (Table 2), but it did not reduce the number of Kupffer cells visible per HPF (Figures 1 and 2). Similar results were obtained in the groups of animals treated with CP only, or with a combination of Lyp and CP. The previous study found that in in vitro culture CP decrease macrophages viability in concentrations higher $>10 \mu \mathrm{M}$, while at $10 \mu \mathrm{M} \mathrm{CP}$ prevented macrophage death induced by lipopolysaccharide [20]. Although we could not determine exact concertation of $\mathrm{CP}$ in liver tissue (or in serum) we could assume that here applied concertation of CP (10 mg/kg) did not reach $10 \mu \mathrm{M}$ which would possibly decrease Kupffer cell number. Also, it is interesting to 
notice that the application of both Lyp and CP had no different impact on cell number than when the two chemicals were applied on their own.

\section{Conclusions}

In the present study, we discovered that 5-day application of lycopene to rats produces a significant decrease in liver tissue physiological inflammatory response (nitric oxide and tumor necrosis factor $\alpha$ concentrations, myeloperoxidase and inducible nitric oxide synthase activity, and CD68 expression) without any negative effect on liver cell function. A single dose of cisplatin also produced a significant diminution in the liver inflammatory response, studied through a panel of same parameters, which this was followed by the disturbance in hepatocytes functioning which was studied through a change in serum liver damage related enzymes activities. Co-administration of lycopene with cisplatin had no significant impact on alterations in liver inflammation levels, however, lycopene was found to prevent hepatocyte damage which arises from cisplatin application. Based on the results of this study we can conclude that lycopene's hepatoprotective activity is not only related to its ability to scavenge free radicals, but also to its ability to modulate tissue inflammatory response.

\section{Acknowledgments}

This work was supported by the Ministry of Education, Science and Technological Development of the Republic of Serbia (grant No. III43012).

\section{References}

[1] Lee CK, Park KK, Hwang JK, Lee SK, Chung WY. The extract of Prunus persicaflesh (PPFE) attenuates chemotherapy-induced hepatotoxicity in mice. Phytother Res 2008; 22: 223-227.

[2] Demir EA, Oz M, Alp MI, Gergerlioglu HS, Nurullahoglu KE, Yerlikaya FH. Coadministration of cisplatin and curcumin does not alter mood-associated behaviors. Bratisl Lek Listy 2016; 117: 106-111.

[3] El-Shitany NA, Eid B. Proanthocyanidin protects against cisplatin-induced oxidative liver

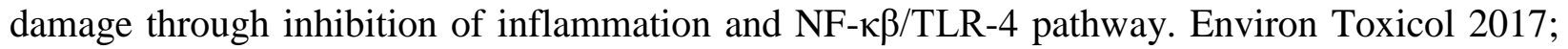
32: 1952-1963. 
[4] Li X, Wang LK, Wang LW, Han XQ, Yang F, Gong ZJ. Cisplatin protects against acute liver failure by inhibiting nuclear HMGB1 release. Int J Mol Sci 2013; 14: 11224-11237.

[5] Oruc E, Kara A, Can I, Karadeniz A, Simsek N. Caspase-3 and CD68 immunoreactivity in lymphoid tissues and haematology of rats exposed to cisplatin and L-carnitine. Kafkas Univ Vet Fak Derg 2012; 18: 871-878.

[6] Roberts RA, Ganey PE, Ju C, Kamendulis LM, Rusyn I, Klaunig JE. Role of the Kupffer cell in mediating hepatic toxicity and carcinogenesis. Toxicol Sci 2007; 96: 2-15.

[7] Adeyemi OS, Meyakno E, Akanji MA. Inhibition of Kupffer cell functions modulates arsenic intoxication in Wistar rats. Gen Physiol Biophys 2017; 36: 219-227.

[8] Hedayati N, Naeini MB, Nezami A, Hosseinzadeh H, Wallace Hayes A, Hosseini S, et al. Protective effect of lycopene against chemical and natural toxins: A review. Biofactors 2019; 45: $5-23$.

[9] Ip BC, Liu C, Lichtenstein AH, von Lintig J,Wang XD. Lycopene and apo-10'-lycopenoic acid have differential mechanisms of protection against hepatic steatosis in $\beta$-carotene-9',10'-oxygenase knockout male mice. J Nutr 2015; 145: 268-276.

[10] Stice CP, Xia H, Wang XD. Tomato lycopene prevention of alcoholic fatty liver disease and hepatocellular carcinoma development. Chronic Dis Transl Med 2018; 4: 211-224.

[11] Akunna GG, Nwafor J, Egwu OA, Ezemagu UK, Obaje G, Adepoju LH, et al. Cisplatininduced ovarian cytotoxicity and the modulating role of aqueous zest extract of Citrus limonium (AZECL) in rat models. Tradit Med Clin Natur 2017; 6: 1-7.

[12] Lowry OH, Rosebrough NJ, Farr AL, Randall RJ. Protein measurement with the folin phenol reagent. J Biol Chem 1951; 193: 265-275.

[13] Radulović NS, Todorovska MM, Zlatković DB, Stojanović NM, Randjelović PJ. Two goitrogenic 1,3-oxazolidine-2-thione derivatives from Brassicales taxa: Challenging identification, occurrence and immunomodulatory effects. Food Chem Toxicol 2017; 110: 94-108. 
[14] Radulović NS, Zlatković DB, Mitić KV, Randjelović PJ, Stojanović NM. Synthesis, spectral characterization, cytotoxicity and enzyme-inhibiting activity of new ferrocene-indole hybrids. Polyhedron 2014; 80: 134-141.

[15] Chistiakov DA, Killingsworth MC, Myasoedova VA, Orekhov AN, Bobryshev YV. CD68/macrosialin: not just a histochemical marker. Lab Invest 2017; 97: 4-13.

[16] Humanes B, Camaño S, Lara JM, Sabbisetti V, González-Nicolás MÁ, Bonventre JV, et al. Cisplatin-induced renal inflammation is ameliorated by cilastatin nephroprotection. Nephrol Dial Transplant 2017; 32: 1645-1655.

[17] Gautier G, Humbert M, Deauvieau F, Scuiller M, Hiscott J, Bates EE, et al. A type I interferon autocrine-paracrine loop is involved in Toll-like receptor-induced interleukin-12p70 secretion by dendritic cells. J Exp Med 2005; 201: 1435-1446.

[18] Khan AA, Alsahli MA, Rahmani AH. Myeloperoxidase as an active disease biomarker: recent biochemical and pathological perspectives. Med Sci 2018; 6: 33.

[19] Pedoto A, Caruso JE, Nandi J, Oler A, Hoffmann SP, Tassiopoulos AK, et al. Acidosis stimulates nitric oxide production and lung damage in rats. Am J Respir Crit Care Med 1999; 159: 397-402.

[20] Chauhan P, Sodhi A, Shrivastava A. Cisplatin primes murine peritoneal macrophages for enhanced expression of nitric oxide, proinflammatory cytokines, TLRs, transcription factors and activation of MAP kinases upon co-incubation with L929 cells. Immunobiology 2009; 214: $197-$ 209.

[21] Omar HA, Mohamed WR, Arab HH, Arafa el-SA. Tangeretin alleviates cisplatin-induced acute hepatic injury in rats: Targeting MAPKs and apoptosis. PLoS One 2016; 11: e0151649.

[22] Rostoka E, Isajevs S, Baumane L, Line A, Silina K, Dzintare M, et al. Effects of lycopene, indole-3-carbinol, and luteolin on nitric oxide production and iNOS expression are organ-specific in rats. Arh Hig Rada Toksikol 2010; 61: 275-285.

[23] Stojiljkovic N, Ilic S, Jakovljevic V, Stojanovic N, Stojnev S, Kocic, H, et al. The encapsulation of lycopene in nanoliposomes enhances its protective potential in methotrexateinduced kidney injury model. Oxid Med Cell Longev 2018; 2018: 2627917. 
[24] Eken MK, Ersoy GS, Kaygusuz EI, Devranoğlu B, Takır M, Çilingir ÖT, Çevik Ö. Etanercept protects ovarian reserve against ischemia/reperfusion injury in a rat model. Arch Med Sci 2019; 15: 1104-1112.

[25] Jedynak M, Siemiatkowski A, Milewski R, Mroczko B, Szmitkowski M. Diagnostic effectiveness of soluble triggering receptor expressed on myeloid cells-1 in sepsis, severe sepsis and septic shock. Arch Med Sci 2019; 15(3):713-721.

[26] Talarowska ME, Kowalczyk M, Maes M, Carvalho A, Su KP, Szemraj J, Gałecki P. Immune to happiness - inflammatory process indicators and depressive personality traits. Arch Med Sci 2019; 16(4): 848-857.

[27] Veeramachaneni S, Ausman LM, Choi SW, Russell RM, Wang XD. High dose lycopene supplementation increases hepatic cytochrome P4502E1 protein and inflammation in alcohol-fed rats. J Nutr 2008; 138: 1329-1335. 


\section{Figure legends}

Figure 1. The average number of macrophages per high power field counted in liver tissue sections obtained from different experimental groups.

Figure 2. Liver macrophages (arrowhead) found on tissue sections obtained from control (A), lycopene treated (B), cisplatin treated (C) and lycopene and cisplatin treated (D) groups (magnification $\mathrm{x} 400$ ) 
Table 1. Serum biochemical parameters obtained from different experimental groups

\begin{tabular}{lllll}
\hline Parameter/Group & $\begin{array}{l}\text { Group I (Vehicle } \\
\text { treated) }\end{array}$ & $\begin{array}{l}\text { Group II } \\
\text { (Lyp treated) }\end{array}$ & $\begin{array}{l}\text { Group III } \\
\text { (CP treated) }\end{array}$ & $\begin{array}{l}\text { Group IV } \\
\text { (CP and Lyp treated) }\end{array}$ \\
\hline ALT (U/L) & $39.8 \pm 1.8$ & $38.8 \pm 4.5$ & $61.3 \pm 11.9^{*}$ & $50.6 \pm 5.1$ \\
AST (U/L) & $89.1 \pm 0.8$ & $99.5 \pm 12.4$ & $273.3 \pm 36.6^{*}$ & $99.5 \pm 1.4^{\#}$ \\
$\gamma$-GT (U/L) & $0.3 \pm 0.2$ & $0.1 \pm 0.1$ & $1.5 \pm 0.1^{*}$ & $0.2 \pm 0.15^{\#}$ \\
\hline
\end{tabular}

Data are presented as mean $\pm \mathrm{SD}, \mathrm{n}=6$; ANOVA, Tuckey's post hoc test ${ }^{*} p<0.001$ vs. Control group (Vehicle animals); ${ }^{\#}<<0.001$ vs. $\mathrm{CP}$ treated group. 
Table 2. Liver tissue inflammatory parameters obtained from different experimental groups

\begin{tabular}{lllll}
\hline Parameter/Group & $\begin{array}{l}\text { Group I (Vehicle } \\
\text { treated) }\end{array}$ & $\begin{array}{l}\text { Group II } \\
\text { (Lyp treated) }\end{array}$ & $\begin{array}{l}\text { Group III } \\
\text { (CP treated) }\end{array}$ & $\begin{array}{l}\text { Group IV } \\
\text { (CP and Lyp treated) }\end{array}$ \\
\hline NO (nmol/mg of proteins) & $8.8 \pm 0.1$ & $2.5 \pm 0.5^{*, \#}$ & $1.6 \pm 0.3^{*}$ & $1.7 \pm 0.5^{*}$ \\
MPO (OD/mg of proteins) & $214.3 \pm 84.5$ & $51.4 \pm 4.5^{*}$ & $39.5 \pm 3.8^{*}$ & $56.4 \pm 7.6^{*}$ \\
TNF- $\alpha$ (pg/mg of proteins) & $29.3 \pm 6.5$ & $7.4 \pm 2.2^{*}$ & $3.2 \pm 1.2^{*}$ & $5.7 \pm 3^{*}$ \\
iNOS (IU/mg of proteins) & $23.6 \pm 8.1$ & $5.4 \pm 1.4^{*}$ & $4.9 \pm 0.4^{*}$ & $6.9 \pm 1.3^{*}$ \\
CD68 (pg/mg of proteins) & $5.7 \pm 3$ & $1.4 \pm 0.4^{*}$ & $0.9 \pm 0.05^{*}$ & $1.7 \pm 0.3^{*}$ \\
\hline
\end{tabular}

Data are presented as mean $\pm \mathrm{SD}, \mathrm{n}=6$; ANOVA, Tuckey's post hoc test $* p<0.001$ vs. Control group (Vehicle animals); ${ }^{\#} p<0.001$ vs. CP treated group. 


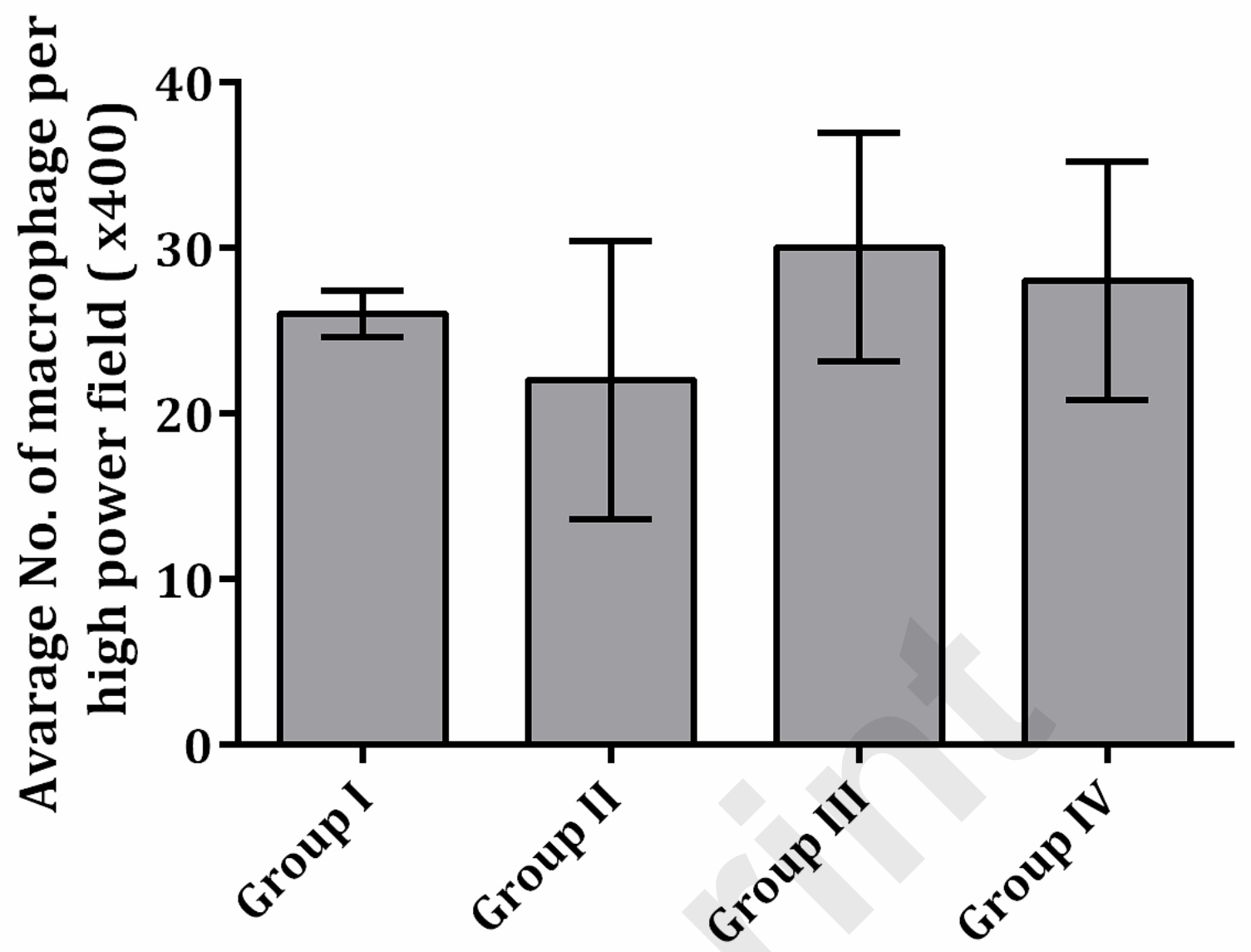

Figure 1. The average number of macrophages per high power field counted in liver tissue sections obtained from different experimental groups. 


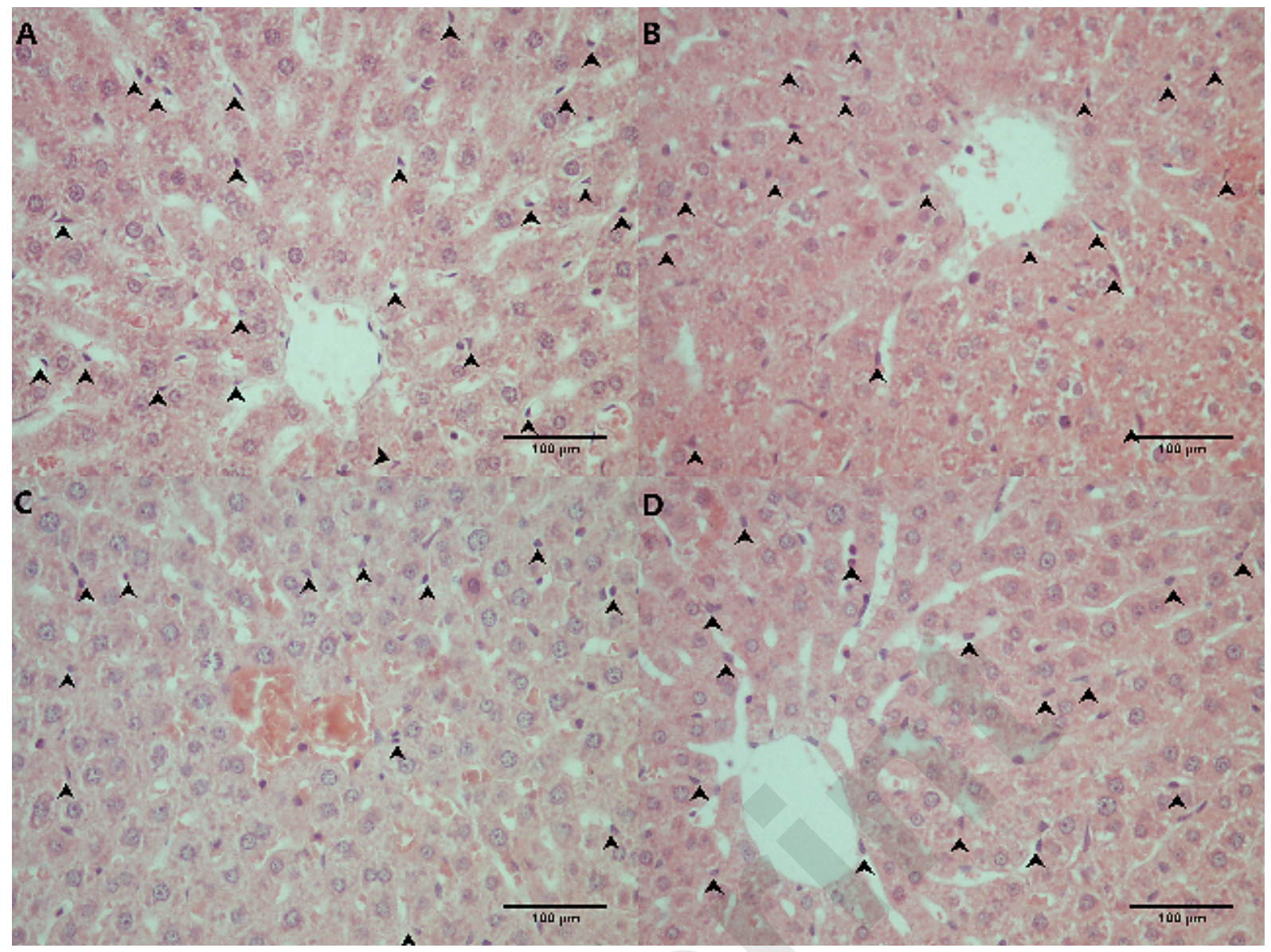

Figure 2. Liver macrophages (arrowhead) found on tissue sections obtained from control $(A)$, lycopene treated $(B)$, cisplatin treated $(C)$ and lycopene and cisplatin treated (D) groups (magnification $\mathrm{x} 400$ ) 